\title{
INTERVENÇÃO CONTEMPORÂNEA DO ESTADO BRASILEIRO: POSITIVAÇÃO DOS IDEAIS NEOLIBERAIS TRABALHISTAS
}

\section{CONTEMPORARY INTERVENTION IN THE BRAZILIAN STATE: POSITIVATION OF THE WORKING NEOLIBERAL IDEALS}

\author{
César Bessa" \\ Andreana Dulcina Platt
}

\begin{abstract}
Resumo: Este estudo visa investigar a hodierna configuração que ocorre junto ao Direito do Trabalho, diante das investidas de ajuste promovidas pelo neoliberalismo que ocorreram nestes últimos quatros anos do Governo Lula. As causas coletivas dos trabalhadores expressas nos textos legais, principalmente as que se referem às perdas nas questões, como "o dissídio coletivo", o "desconto em folha" e na ampliação do módulo semanal de trabalho, fomentada pela abertura do comércio aos domingos, serão aqui destacadamente analisadas.
\end{abstract}

Palavras-chave: Neoliberalismo. Direito do Trabalho. Legislação.

Abstract: This study aims at investigating the current configuration of Work Rights, bearing in mind the adjustment attempts promoted by Neoliberalism that occurred in the last four years of President Lula's government. The workers' collective claims expressed in the legal texts, mainly the ones referring to losses in issues such as the "collective agreement", the "payroll withholding", and in the extension of the weekly work period, fomented by the opening of shops on Sundays, will be analyzed in detail in this work.

Keywords: Neoliberalism. Work Rights. Legislation.

Mestre em Direito Negocial pela UEL/PR. Professor do Departamento de Direito Público da UEL/PR. e-mail: bess@sercomtel.com.br

Doutora em Educação pela UNICAMP/SP. Professora do Departamento de Educação da UEL/PR. Graduanda em Direito pela PUC/PR. Pós-Graduanda em Direito pela UEL/PR. e-mail: adplatt@uel.br 


\section{INTRODUÇÃO}

O presente estudo versa pela análise aos hodiernos mecanismos neoliberais à organização do Estado brasileiro que se dá por meio de um confronto às históricas conquistas expressas no Código trabalhista. Para tanto, resgataremos historicamente as bases da caminhada neoliberal e suas entranhas no corpo estatal, e, após, refletiremos de forma mais acurada sobre o programa que se encaminhou nos últimos quatro anos e que diz respeito precipuamente ao "desconto em folha nos salários dos trabalhadores", a "jornada de trabalho aos domingos pelos comerciários" e o óbice que se cria aos "sindicatos e o acesso à justiça”.

\section{A TRAJETÓRIA DA SAGA NEOLIBERAL: REVISITAÇÃO AO MODO DE PRODUÇÃO CAPITALISTA E SUA IMPLICAÇÃO NO ESPAÇO ESTATAL}

Ao discutir sobre os elementos que compõem a trajetória do movimento político-econômico neoliberal, entendemos como pertinente revisitar os elementos que determinaram as condições para seu "acolchoamento" nas diversas nações, assim como a compreensão daquilo que se chamou de "neoliberalismo periférico" quando tratarmos especificamente do caso brasileiro (TAVARES, 1997).

\subsection{A Reestruturação “Necessária”}

Após inúmeras revoluções políticas originadas da consolidação do modelo na produção capitalista, desde a introdução do primeiro grande invento tecnológico que multiplicou as possibilidades da geração de produtos (máquina a vapor) e por produção de escala industrial, há de se falar também na consolidação de uma formação social do tipo capitalista (SINGER, 1998).

O formato não pacífico das conquistas civis pela nova classe que surgia a dos operários das fábricas - implicava na "total destruição" de outras esferas de trabalhadores originais à produção agrícola e artesanal, debilitando seus conhecimentos ao vulgo de "desqualificados" ou "semiqualificados" quando estes possuíam direitos econômicos e políticos por atividades atribuídas a mestres e oficiais. Apenas o exemplo dessa ruptura na composição social entre os indivíduos e seus conhecimentos, na organização de sua existência e o novo modelo que aglutina uma nova lógica de produção (em resposta a esta mesma existência, do consumo e de conhecimentos que urgem em serem aprendidos, de modo que os trabalhadores incorporem habilidades para a manipulação dos maquinários), já é suficiente para que compreendamos a sua repercussão na ampla esfera social. 
Podemos falar, portanto, que um dos elementos que produz a crise do sistema capitalista está na esfera da recomposição dos direitos dos trabalhadores com vistas a melhores condições de trabalho e ganhos, frente ao acúmulo estupendo das empresas. Estes, para garantir minimamente sua dignidade frente a exploração de sua mão-de-obra pelas classes dominantes e do empresariado que se beneficia da mais valia expropriada, intensificam ao longo da história, as lutas para conquista e ampliação de seus direitos civis, como relatado acima por Singer (1998).

Segundo Singer (1998), o modelo de produção capitalista tem ao longo de sua história produzido seguidas crises, que urgem por reestruturações com o objetivo de realinhar a produção - e sua variedade, o consumo, o acúmulo de ganhos e a sua ampliação a mercados cada vez mais específicos e "distantes". Podemos descrever que o Estado, em suas funções precípuas, foi o que pacificou esses momentos de crise com o uso de sua estrutura político-jurídica.

Enquanto marcos históricos da sociedade moderna têm-se registrado até então, o volume de três grandes crises mundiais do sistema capitalista: a) crise do modelo de produção clássico ou a Primeira Revolução Industrial, b) Crise do modelo taylorista/fordista de produção (anos 30), c) Introdução do modelo toyotista de produção (anos 70). Tais crises originaram o movimento daquilo que a literatura denomina de "reestruturação do modelo de produção". Porquanto o capital ser reconhecidamente um "processo"1, ele visa a realimentação não só do próprio capital, mas de um modo de vida social, ou seja, ele interpenetra na condição de existência dos indivíduos, por meio dos produtos que distribui ao consumo, promovendo novos desejos e necessidades (HARVEY, 2000). A reestruturação produtiva é uma forma de revitalização ao processo capitalista que, segundo o autor citado, diz respeito a:

[..] regras internalizadas de operação (que) são concebidas de maneira a garantir que ele (capitalismo) seja um modo dinâmico e revolucionário de organização social que transforma incansável e incessantemente a sociedade em que está inserido. $\mathrm{O}$ processo mascara e fetichiza, alcança crescimento mediante a destruição criativa [...], explora a capacidade de trabalho e do desejo humanos, transforma espaços e acelera o ritmo da vida. Ele gera problemas de superacumulação para os quais há apenas um número limitado de soluções possíveis. (HARVEY, 2000, p. 307, grifos nosso).

${ }^{1}$ Para Harvey (2000, p.307) “o capital é um processo, e não uma coisa”. 
Para Huberman (1986) e Dias (1999), é preciso esclarecer que a reestruturação produtiva é reconhecidamente um remédio às crises de supra-acumulação e que serve em dada época histórica e em determinado espaço, de tal sorte que os aspectos infra-estruturais quanto supra-estruturais estejam concordantes, a ponto da existência dos indivíduos não ser objetivada de outra possibilidade, partindo do imaginário popular. Conforme Soja (1993, p. 193), num sentido ampliado, a reestruturação vem a ser uma "freada" ou recomposição por "mudança em direção a uma ordem e a uma configuração significativamente diferente da vida social, econômica e política”. Pressupõe, também, que a antiga ordem esteja "esgarçada para impedir os remendos adaptativos convencionais e exigir, em vez deles, uma expressiva mudança estrutural”. Foi o que ocorreu com toda a ordem econômica mundial, desde o período da Primeira Revolução Industrial, quando não somente o modo de produzir e distribuir os produtos destacadamente se alterou, mas também na organização social que tal alteração demandou.

Segundo Singer (1998, p. 11), a crise da década de 1930, no pós-guerra, opera com uma importante singularidade: a presença forte do Estado em resgate a economia. É a fase do "capitalismo dirigido", iniciado com a tomada da social-democracia nos governos de economias centrais, como a Suécia. Neste período, o Estado foi denominado de "Bem-Estar Social”, compensando os baixos salários com "benefícios", negociando com centrais sindicais, estabelecendo, assim, uma inovadora articulação entre mercado e Estado, com vistas ao "pleno aproveitamento dos recursos".

O último período destacado, neste breve resgate histórico ao processo de reestruturação produtiva, vem a ser a crise da década de 1960-1970. Celebrado enquanto um período de grande prosperidade, o capitalismo mundial teve significativos ganhos, principalmente na recolocação dos indivíduos ao mercado de trabalho ocasionado por uma "quase estabilidade estrutural" (SINGER, 1998). Essa ampliação de direitos se estende para importantes revoluções, principalmente no campo da cultura e da política. A crise se apresenta com o confronto dos fundamentos capitalistas (que independente do formato do estado, nunca se alteram) que se recrudescem pela oposição agora material do denominado "socialismo real". O autor lembra que no período conhecido com o "Welfare State", houve a possibilidade da expansão de empresas multinacionais (principalmente Estados Unidos) em vários espaços do planeta, concebendo-se aquilo que denominávamos como "globalismo dirigido" (SINGER, 1998).

A produção capitalista urge por uma readequação, uma vez que a pressão inflacionária decorrente dos "conflitos distributivos" demandava uma nova 
oxigenação por meio da abertura de mercados - livres do dirigismo estatal. Nesta "onda", o Estado é "demonizado" e a ordem mundial exige que em níveis macroeconômicos as teses econômicas de Friedman fossem amplamente desenvolvidas, aplicando-se aos mercados locais a flexibilização, que, no campo $\mathrm{da}$ indústria propriamente dita se organizava pelo desenvolvimento tecnológico e logístico do modelo "toyotista".

O modelo toyotista significa o conjunto de procedimentos industriais, denominados também de produção "just in time"2 (ou "em tempo"), no qual a organização da empresa, em seus diferentes pontos (da produção à distribuição do produto para consumo), supera seu antigo modelo de estocagem, vedete do processo anterior. Segundo Harvey (2000, p. 140-141), o modelo de “acumulação flexível” demanda uma nova referência que se apóia:

[...] na flexibilidade dos processos de trabalho, dos mercados de trabalho, dos produtos e padrões de consumo. Caracteriza-se pelo surgimento de setores de produção inteiramente novos, novas maneiras de fornecimento de serviços financeiros, novos mercados e, sobretudo, taxas altamente intensificadas de inovação comercial, tecnológica e organizacional. [...] a acumulação flexível parece implicar níveis relativamente altos de desemprego "estrutural” [...], rápida destruição e reconstrução de habilidades, ganhos modestos (quando há) de salários reais [...] e o retrocesso do poder sindical - uma das colunas políticas do regime fordista.

Parte daí o necessário reajuste jurídico-institucional para a inserção do novo modelo de produção e consumo, e, assim, conformar não só os determinantes objetivos para a sobrevivência dos indivíduos (ou infra-estrutural), mas os quesitos nevrálgicos do aparato subjetivo (ou supra-estrutural), com vistas a reificação do novo modelo de existência por meio de valores e símbolos, na cotidianidade de forma ampla. Segundo Harvey (2000, p. 148), esta "nova ordem produtiva" se instala em busca do reequilíbrio das bases do capital por meio "da aceleração do tempo e do giro de produção [...] sem a redução do consumo"

${ }^{2}$ Segundo Leite (1994, p. 568) "o just in time é um instrumento de controle da produção que busca atender à demanda da maneira mais rápida possível e minimizar os vários tipos de estoque da empresa (intermediários, finais e de matéria-prima). O sistema pode tanto abarcar a relação da empresa com seus fornecedores e consumidores (just in time externo) como apenas os vários departamentos e setores que compõem uma mesma empresa (just in time interno)". Para Bernardes (1998, p. 38) a flexibilidade produtiva não estaria atrelada a este instrumento de controle ("just in time"), mas "à capacidade de conduzir uma trajetória de inovação tecnológica em condições de incertezas quanto ao futuro”. 
O autor ainda denuncia que, por ser acompanhada pela ponta do consumo, a acumulação flexível torna o mundo envolto a modas cada vez mais fugazes "e pela mobilização de todos os artifícios de indução de necessidades e transformação cultural que isso implica”. Harvey (2000) agudiza sua análise quando retrata um importante elemento desses novos tempos sociais: "a estética relativamente estável do modernismo fordista cedeu lugar a todo o fermento, instabilidade e qualidades fugidias de uma estética pós-moderna que celebra a diferença, a efemeridade, o espetáculo, a moda e a mercadificação das formas culturais” (p. 148).

Toda essa estrutura que "acolchoa" o reequilíbrio da ordem econômica mundial possui um "cérebro" político arguto, que conduz importantes modificações que se fazem necessárias à adequação produtiva do capital, em cada Estado-nação: as políticas neoliberais. Para Ianni (1998, p. 29), a estrutura de poder na modernidade tem se materializado em cada país local por meio das chamadas agências multilaterais, ou como o autor cita, por "corporações transnacionais". Dentre as mais portentosas, podemos citar o Fundo Monetário Internacional (FMI), o Banco Mundial (ou Banco Internacional de Reconstrução e Desenvolvimento/BIRD) e a Organização Mundial do Comércio (OMC).

Segundo Ianni (1998, p. 29):

(estes organismos) dispõem de recursos financeiros, técnicos e organizatórios, mobilizando ciência e técnica, equipes e aparatos, para diagnosticar, planejar e pôr em prática decisões que influenciam as economias de cada uma e todas as ações, assim como da economia mundial. A sua capacidade de estabelecer critérios e diretrizes, não só econômico-financeiras, mas também técnicoorganizatórias e outras, aos quais devem ajustar-se os governos nacionais, lhes confere a categoria de estruturas mundiais de poder.

\subsection{A Reestruturação Produtiva “à brasileira”}

No Brasil o marco do processo de acumulação flexível se deu com a "aurora" da década de noventa do século passado. Porém, sua presença seria percebida desde meados da década de oitenta, conforme Leite (1994), com a introdução de dois novos formatos na organização do trabalho - a implantação dos CCQs (Círculos de Controle de Qualidade) -, que operou primeiramente entre trabalhadores mais especializados para em seguida romper em diferentes setores, e a introdução de novas tecnologias.

A autora lembra que a introdução dos CCQs esteve atrelada ao movimento político dos trabalhadores desde idos de setenta, uma vez que o afã de 
participação, conquistado pelos trabalhadores em seu processo reivindicatório ${ }^{3}$, urgia (segundo a ótica do empresariado) por modelos mais elaborados de controle.

Quanto ao desenvolvimento tecnológico, a partir de 1989, dados coletados atestam que se deram importantes investimentos neste setor, no parque industrial brasileiro (LEITE, 1994).

Embora esses elementos preconizassem uma ruptura do modelo fordista de produção para a produção do tipo toyotista, Leite (1994) asserta que não houve grandes alterações no campo da organização do trabalho, uma vez que houve uma "releitura" (ou adaptação) do modelo internacional de inovação tecnológica e organizacional da produção "just in time” pelo empresariado brasileiro, corrompendo a essência de conceitos como "esquemas participativos”, uma vez que se desautorizava a tomada de decisão dos indivíduos, a "polivalência" que seria traduzida na capacidade de controlar mais de uma máquina ao mesmo tempo, etc, e não somente isso, mas a caracterização de uma "just in time taylorizado" entre gerência e trabalhadores, "onde as estratégias careciam do envolvimento e compromisso, dependendo mais da coerção e da pressão sobre os trabalhadores” (LEITE, 1994, p. 570).

A partir dos anos 90, como anteriormente pontuamos, o Brasil incorporou enquanto política de Estado, os principais fundamentos da nova ordem econômica mundial, preconizada pelos novos liberais e pelos novos conservadores $^{4}$, com o propósito de realinhar a economia mundial que estagnara numa crise advinda desde a década de setenta, século XX. O principal motor dessa política estava no fundamento do "Estado Mínimo" quanto aos assuntos do mercado. Sua principal justificativa consistia que o Estado de Bem-Estar Social, que nem havia se incorporado devidamente aqui no país (IANNI, 1998), estaria "dificultando" as possibilidades de crescimento e

${ }^{3}$ A lembrança de que o modo de produção capitalista, com seu respiro promovido pelo processo de reestruturação, aduz a uma nova organização social e que sempre se supera em outros dados da existência social. Esse movimento, num sentido espiral e dialético, se dá pelos confrontos entre os diferentes interesses de classe e pela distribuição da riqueza produzida pelos trabalhadores, que segundo a tese sustentada até aqui, é o principal foco que promove para as modificações jurídico-institucionais.

${ }^{4} \mathrm{~A}$ aliança entre os novos liberais (ou neoliberais) e os novos conservadores (ou neoconservadores) se chamará de "Aliança da Nova Direita" e se iniciou a partir da primeira metade da década de setenta, do século passado. Sobre esse assunto consultar Cueva (1989) e Boron (1999). 
desenvolvimento econômicos, uma vez que havia uma centralidade das ações estatais naquilo que o mercado deveria promover por si (como os serviços de saúde, educação, terceirizações, alimentação, energia, comunicação, extração de minérios e matéria-prima, etc), a partir da concorrência de preços e na liberdade de contratar.

Francisco de Oliveira (2000, p. 24) aponta que a última década dos anos noventa após os ventos da empreitada neoliberal e a partir da eleição do "caçador de marajás” (era Collor) sucede-se o escopo para atrelar a necessária transformação do Estado. O Estado deveria "sair" de uma condição de parasita da economia, promotor da má distribuição de renda e da situação em que se encontravam os serviços básicos da política social, para aquele em que

o resultado (seja) o radical enfraquecimento do Estado, cada vez mais submetido aos interesses das classes dominantes e renunciando a graus importantes de soberania nacional diante da superpotência imperial, a grande burguesia transnacionalizada e suas 'instituições' guardiãs: o FMI, o Banco Mundial e o regime econômico que gira em torno da supremacia do dólar. (BORON, 2000, p. 78).

\section{AS PRINCIPAIS ATUALIDADES DO PROGRAMA NEOLIBERAL NO DIREITO TRABALHISTA BRASILEIRO}

O Direito do Trabalho estuda o ordenamento jurídico moldado pela civilidade cultural para regular as relações de emprego na vida cotidiana; ou seja, a vida pensada em sociedade convencionou condições mínimas para que, por meio de um contrato, uma pessoa possa explorar o trabalho de outra pessoa. Essas condições mínimas são critérios culturais, políticos, econômicos e predominantes de convencimento de uma relação equilibrada pelo conceito do que é justo. Se, verdadeiramente, é justa a relação jurídica de emprego, não é o caso da discussão que pretendemos discorrer adiante.

A necessidade da normatização de regras mínimas de trabalho resultou das contradições da revolução industrial, especialmente da constatação da indignidade das condições de trabalho acometidas aos homens, às mulheres e às crianças. Esses reflexos desumanos ocasionados com a estratificação do novo sistema de produção econômica provocaram conflitos sociais que, após inúmeras lutas das camadas oprimidas, deflagraram um marco histórico, a criação da Organização Internacional do Trabalho (OIT) gerada por meio do Acordo da Sociedade das Nações e pelo Tratado de Versalhes em 1919 (OLEA, 1997). Ali, ficaram convencionadas regras tidas como universais que deveriam 
ser globalizadas e estimuladas como regras jurídicas a serem adaptadas nos países membros.

A despeito de todas as discussões sobre as possíveis contradições que se possa mensurar a respeito das verdadeiras causas do nascimento da OIT e seu tom conciliador de um programa favorável ao capitalismo internacional, é inegável que as regras jurídicas sugeridas são, também, manifestações de conquistas das lutas dos trabalhadores para preservação mínima de dignidade humana nas relações de trabalho, como regras coercitivas que venham, por exemplo, entre outras conquistas, impor: a duração máxima de trabalho humano, o direito de descanso ocasionado pelo trabalho, a garantia do salário mínimo que preserve sustento de uma pessoa e sua família, a garantia da associação sindical, etc.

Nas regras jurídicas que disciplinam as relações de trabalho há um reconhecimento racional de que nelas - regras jurídicas - contêm, de forma embrionária, um princípio jurídico: o princípio protetor, destinado à preservação das condições mínimas da dignidade da pessoa humana.

Este princípio, que é manifestamente o princípio da igualdade, está inscrito nos primeiros artigos da principal legislação nacional, a Constituição Federal, seja entre os fundamentos da República em Estado Democrático de Direito (art. 1ㄹ. .) de que deve preservar a dignidade da pessoa humana (inciso III) e os valores sociais do trabalho (inciso IV), bem como em inúmeras disposições previstas na parte que discorre sobre Dos Direitos e Garantias Fundamentais (Título II), por meio do art. 5ª . (Capítulo I - Dos Direitos e Deveres Individuais e Coletivos) e, especialmente, do art. 7a. e art. 8a․ (Capítulo II - Dos Direitos Sociais).

Pois bem, reconhecida as razões das normas jurídicas protetivas impostas pelo Estado e que se interferem na liberdade contratual nas relações de trabalho, verifica-se que o atual governo, midiaticamente denominado de Governo Lula, cedeu a alguns apelos das forças neoliberais, enfraquecendo e desregulamentando a proteção jurídica nos salários, na duração semanal de trabalho e no acesso ao judiciário pelos sindicatos.

\subsection{Descontos nos Salários dos Trabalhadores}

No que tange à proteção jurídica aos salários há inúmeras manifestações regulamentares na legislação infraconstitucional, por exemplo: Irredutibilidade, Inalterabilidade, Impenhorabilidade, Impossibilidade da cessão do salário, Garantia do salário mínimo, Periodicidade, Pontualidade (época, momento, local, forma e certeza do pagamento), etc. Todos esses meios de proteção são orientados por convenções e sugestões da OIT. Para o debate aqui travado, 
importa o princípio protecionista chamado de Integralidade Salarial. Este princípio é uma espécie de intangibilidade do salário, para que o mesmo seja pago em sua totalidade, sem descontos impróprios e abusivos em favor do empregador ou de qualquer outra pessoa.

No plano internacional, a Convenção $\mathrm{n}^{\underline{a}} 95^{5}$ da OIT trata da questão e, posteriormente, a Convenção $\mathrm{n}^{\mathrm{a}} 117^{6} \mathrm{da}$ OIT. E no sistema ordinário jurídico nacional, confirmando a legislação internacional, dispõe a CLT:

Art. 462. Ao empregador é dado efetuar qualquer desconto nos salários do empregado, salvo quando este resultar de adiantamentos, de dispositivos de lei ou de contrato coletivo.

[...]

\$4 - Observado o disposto neste Capítulo, é vedado às empresas limitar, por qualquer forma, a liberdade dos empregados de dispor do seus salário.

Verifica-se pela própria leitura do $\S^{4^{\underline{a}}}$ acima mencionado, que o princípio em debate encontra seu respaldo não só na natureza jurídica de crédito alimentar do trabalhador, mas também e, de forma expressa, na preservação da natureza jurídica da personalidade do trabalhador em poder dispor de seu salário.

$\mathrm{Na}$ ordem jurídica a regra básica é de vedação a descontos empresariais no salário do trabalhador, proteção ampliada com a promulgação da Constituição Federal de 1988, e que estipula que a retenção dolosa do salário constitui crime (art. 7aㅡ, X) que para considerável parte da doutrina a regra constitucional não é ineficaz, porque o tipo penal da apropriação indébita (art. 168, Código Penal) é plenamente ajustável à hipótese aos casos incontroversos de retenção dolosa do salário básico (DELGADO, 2007, p. 770)7

${ }^{5}$ Art. 8. 1. Descontos em salários não serão autorizados, senão sob condições e limites prescritos pela legislação nacional ou fixados por convenção coletiva ou sentença arbitral. 2. Os trabalhadores deverão ser informados, de maneira que a autoridade competente considerar mais apropriada, sobre condições e limites no quais tais descontos puderem ser efetuados.

${ }^{6}$ Art. XI - 1. [...] 8. Serão tomadas todas as medidas práticas e possíveis no sentido de que:

a) os trabalhadores sejam informados de seus direitos em matéria de salário;

b) sejam impedidas quaisquer deduções não-autorizadas dos salários;

c) os montantes dedutíveis do salário a título de suprimentos e serviços, os quais constituam parte integrante do salário, sejam limitados a seu justo valor em espécie.

${ }^{7} \mathrm{O}$ entendimento lançado, de apropriação indébita, parece-nos equivocado, uma vez que fere o princípio da anterioridade, da reserva legal e do Estado Democrático de Direito. 
Cumpre esclarecer que desconto salarial é uma subtração efetuada pelo empregador no salário do trabalhador que importa em redução salarial. Tais descontos só poderão resultar de dispositivo de lei, negociação coletiva e por contrato individual, desde que para atender a três finalidades: necessidades ou interesses do empregador (por danos patrimoniais causados pelo empregado), do terceiro alimentando (pensão alimentícia) e dos interesses do trabalhador.

Não sendo autorizado por lei ou negociação coletiva, o desconto em favor dos interesses do empregado poderá ser efetuado mediante autorização individual do trabalhador, como para planos de seguro de vida e previdência complementar, assistência odontológica, médico-hospitalar, entidade cooperativa, cultural, recreativa e despesas com alimentação e habitação (art. 458, §§2 $2^{\underline{a}}$. e $3^{\underline{a}}$, CLT).

E não poderia ser de outro modo, pois, se o preceito legal fosse rígido, redundaria em prejuízo para aqueles a quem procura beneficiar (GOMES, 1996).

No entanto, comentando sobre o vício de vontade, Cesarino Júnior (1993) destaca que será do empregado o ônus da prova da intenção fraudulenta e dissimulada, pois só merece louvores o empregador que se mostra preocupado com o atendimento satisfatório das necessidades vitais de seus empregados. Mas, saliente-se, é comum o empregado ser coagido, já no ato da admissão, a fazer parte de algum tipo de plano ou associações.

Os descontos em favor dos interesses do empregado também poderão ser em benefício da entidade sindical da categoria do trabalhador, sendo assim, um desconto em benefício indireto do empregado (NASCIMENTO, 1991, p. 207) por meio de imposto sindical (arts. 578 a 610, CLT), mensalidade sindical (art. 545, CLT), taxa assistencial (art. 513, "e", CLT) e contribuição confederativa (art. $\left.8^{\underline{a}}, \mathrm{IV}, \mathrm{CF}\right)$.

Tem-se assim, que o fundamento da integralidade salarial é de proteção contra abusos do empregador, contra terceiros e contra a própria imprevidência do trabalhador que pode ser iludido pelas imagens facilitadoras do consumismo e, com isso, desequilibrar o seu orçamento doméstico com prejuízo para si e para sua família.

Com advento da Medida Provisória n. 130, de 17-9-2003, pelo Decreto n. 4.840, da mesma época, e da Lei n. 10.820, publicada dois meses depois, os trabalhadores podem autorizar, de forma irrevogável e irretratável, o desconto em folha de pagamento dos valores referentes ao pagamento de empréstimos, financiamentos e operações de arrendamento mercantil em favor de instituições financeiras e sociedades de arrendamento mercantil (art. 1a. .). 
Referida autorização pelo trabalhador obriga o empregador a efetuar o desconto em folha de pagamento e repassar o valor à instituição financeira (art. $3^{\underline{a}}$ e $5^{\underline{a}}$.), cujo limite contratado não poderá exceder a $30 \%$ do salário disponível do trabalhador (art. $2^{\mathrm{a}}$.).

A tutela que havia anteriormente não impedia a liberdade do trabalhador dispor de seu salário. Ele poderia consumir, emprestar, financiar, etc. O que não era possível era o empregador efetuar descontos diretos no salário do trabalhador para favorecer interesses de terceiros; em outras palavras, instituto salário era assegurado de forma intocável na folha de pagamento.

Agora, havendo a autorização do trabalhador, mesmo que arrependa-se em pagar o seu financiamento a fim de preservar seu orçamento doméstico, mesmo assim, o empregador manterá o desconto. A intangibilidade salarial que tanto preserva a natureza alimentar do trabalhador foi abalada em proveito do capital especulativo. Mesmo porque o trabalhador não só pagará a dívida, mas também juros dessa dívida em benefício de um credor que se enriquece na desproporção contratual.

É claro que a autorização para desconto vai até o limite de $30 \%$ do salário disponível ${ }^{8}$, preservando, parcialmente, a natureza alimentar do salário. A integralidade salarial persiste enquanto proteção legal e geral, porém, abriu-se uma exceção apenas para favorecer o mercado financeiro. Portanto, caso o trabalhador não queira um financiamento do banco, mas comprar em qualquer empresa comercial, emprestar parte de seu salário, doar mensalmente para igreja ou instituição de caridade por intermédio de desconto direto na folha de pagamento do salário, ele não pode. Essa autorização só é possível, como já foi dito, exclusivamente, para o mercado financeiro.

As centrais sindicais defenderam os descontos por meio de empréstimos bancários, advogando o atendimento aos interesses dos próprios trabalhadores. Contudo, o argumento torna-se contraditório diante da seguinte indagação: por que os descontos só podem ser autorizados em favor do mercado financeiro?

O que se vê, aliás, é uma nítida discriminação negativa dos empresários

${ }^{8}$ Para o texto legal do Decreto n. 4.840, de 17 de setembro de 2003, considera-se remuneração disponível a parcela remanescente da remuneração básica após a dedução das consignações compulsórias efetuadas a título de contribuição previdenciária, pensão alimentícia judicial, imposto sobre rendimentos do trabalho, decisão judicial ou administrativa, mensalidade e contribuição em favor de entidades sindicais, outros descontos compulsórios instituídos por lei ou decorrentes de contrato de trabalho (art. $\left.2^{\underline{a}}, \S 2^{\underline{a}}\right)$. 
que não pertencem ao mercado financeiro, enquanto aqueles que pertencem a essa ciranda passaram a ter um novo foco de exploração de seus juros, cuja segurança de recebimento é assegurada pela folha de pagamento de salários.

Esse expediente legal já vinha sendo desenvolvido no período do Governo FHC, patrocinando os descontos, da mesma forma, nos vencimentos dos servidores públicos e dos aposentados. Verifica-se que o Governo Lula deu continuidade ao programa de auxílio ao mercado financeiro que passou a ter um crédito seguro e não volátil.

\subsection{O trabalho aos domingos para os comerciários}

A questão do trabalho aos domingos está relacionada com a limitação da duração do trabalho semanal e com o repouso devido ao mesmo período. Diversas são as causas à limitação imposta pelo sistema normativo, classificadas aqui como:

a) Fundamentos históricos: em razão da indignidade de jornadas extensivas que provocaram conflitos entre trabalhadores e empregadores, cuja normatização encontra relevância na Convenção da OIT de $n^{2}$. 1, em 1919, que limitou a jornada de 8 h diárias e de 48h semanais. Em 1935, ainda buscando normatizar uma jornada condigna, a OIT aprovou a Convenção $\mathrm{n}^{\mathrm{a}} 47$ propondo o módulo semanal de $40 \mathrm{~h}$, instrumento esse que foi ratificado por poucos países, dentre os quais não se inclui o Brasil, cujo aparato legislativo só vai iniciar-se a partir de 1932 em relação ao comércio e indústria e depois gradativamente a outros setores, até 1934, quando a Constituição Federal assegurou a jornada de trabalho não excedente de $8 \mathrm{~h}$.

b) Fundamentos biológicos: para combater os problemas físicos, psíquicos e acidentes de trabalho provenientes da fadiga no serviço. $O$ limite da duração do trabalho constitui medida profilática, por isso a $\mathrm{CF} / 88$ prevê a redução dos riscos inerentes ao trabalho, por meio de normas de saúde, higiene e segurança (art. 7aㅡ, XXII), assim, a modulação da duração do trabalho é parte integrante de qualquer política de saúde pública, uma vez que influência a eficácia das medidas de medicina e segurança adotadas nas empresas (DELGADO, 2007, p. 833).

c) Fundamentos sociais: visam possibilitar ao trabalhador viver socialmente na coletividade a que pertence, usufruindo de atividades recreativas, culturais, religiosas, esportivas, etc, aprimorando seus conhecimentos, convivendo com a família e comunitariamente; por meio dessa integração social o indivíduo absorve valores sociais e, portanto, a concepção do bem comum. 
d) Fundamentos econômicos: estabelecem que a limitação da jornada contribui para aumentar a produtividade e combatem o desemprego. A redução da duração do trabalho abre automaticamente postos de trabalho e com a diminuição do trabalho de forma correlata há diminuição dos riscos da infortunística do trabalho diminuindo, por consequêencia, o custo previdenciário para toda a sociedade (DELGADO, 2007, p. 836).

Por sua vez, constituídos pelo sistema normativo, os repousos, intervalos ou descanso, são lapsos temporais regulares que entrecortam a duração do trabalho, relacionam-se com o dia de trabalho (descanso intra e interjornadas), com a semana trabalhada (repousos semanais ou em feriados) e com o ano trabalhado (férias anuais).

Nossa atenção se volta para o repouso relacionado com a semana trabalhada, cujos fundamentos são os mesmos da limitação da duração do trabalho. A este seja incluído forte influência cultural e de origem religiosa, cujo relato Bíblico é retratado no livro de Gênesis 2:2, donde se verifica que necessário seria observar o dia do descanso: "e descansou no sétimo dia, depois de ter acabados as suas obras". A doutrina registra que o repouso semanal foi observado em todas as épocas históricas, inclusive aos escravos, mas com a Revolução Industrial houve regressão e tal prática passou a ser pauta constante das reivindicações dos trabalhadores.

No plano do Direito Internacional, o Tratado de Versalhes, em 1919, registrou no art. 427, item 5ª "o propósito de assegurar a adoção de um descanso de vinte e quatro horas, sempre que possível aos domingos"; e, na OIT, as Convenções n⿳亠丷a 14, de 1921 e a de $n^{a}$. 106, de 1957, tratam do repouso semanal, além de outras Convenções que cuidam incidentalmente do descanso semanal (ns. 31, 57, 67, 76 e 110).

No Brasil, na esfera constitucional, a matéria só veio a lume em 1934, repetindo-se em todas as posteriores. Na legislação ordinária, a matéria foi tratada por leis e decretos a partir de 1932 (comerciários, transportes, etc), até ser aprovada a CLT, em 1943, cuja redação legal ${ }^{9}$ está em vigor. O dispositivo celetista, contudo, resguarda a concessão ao descanso semanal de $24 \mathrm{~h}$ consecutivas, mas não trata da sua remuneração. Essa questão, de remuneração ao repouso semanal, só veio a se incorporar a nossa legislação de 1949, por meio da Lei 605 de $05.01 .49^{10}$ e pelas demais constituições federais ${ }^{11}$.

\footnotetext{
${ }^{9}$ Art. 67. Será assegurado a todo empregado um descanso semanal de 24 (vinte e quatro) horas consecutivas, o qual, salvo motivo de conveniência pública ou necessidade imperiosa do serviço, deverá coincidir com o domingo, no todo ou em parte.
} 
A CLT, por intermédio do art. 67, excepciona o trabalhado realizado aos domingos por motivo de conveniência pública ou necessidade imperiosa do serviços, acrescentando o parágrafo único que nesse caso "será estabelecida escala de revezamento, mensalmente organizada e constando do quadro sujeito a fiscalização”, visando permitir que com certa freqüência o repouso coincida com o domingo, sendo que nesse sentido são profícuos os regulamentos ministeriais que cuidam do assunto.

A Lei 605/49 refere-se à concessão do repouso "preferencialmente aos domingos”, assim como a CF/88, desde que nos limites das exigências técnicas das empresas, esclarecendo que exigências técnicas são condições peculiares da empresa ou em razão do interesse público que tornem indispensável a continuidade do serviço (parágrafo único, art. 5ㅜㅡ.).

Regulamentando a Lei 605/49, o Decreto 27.048/49, considera que, de acordo com as exigências técnicas de algumas empresas, torna-se indispensável a continuidade dos serviços prestados aos domingos e de acordo com o interesse público, relacionou e autorizou diversos setores ${ }^{12}$ ao funcionamento regular aos domingos. Assim, sendo impossível a coincidência da folga semanal com o domingo, impõe-se à empresa conceder folga compensatória em outro dia da semana. Sem a folga compensatória, por força do o art. 9 ${ }^{a 13}$ da Lei 605/ 49 é devido o pagamento em dobro pelo trabalho realizado em tais dias.

Sem qualquer critério, o governo de Fernando Henrique Cardoso (FHC) editou a Medida Provisória (MP) 1.539-34, de 07.08.97, autorizando o trabalho do comércio em geral aos domingos, mas o Supremo Tribunal Federal (STF), por meio de uma Ação Direta de Inconstitucionalidade (Adin 1.650-4), deferiu liminar sustando seus efeitos, porque dispensava a negociação coletiva

${ }^{10}$ Art. 1․ . Todo empregado tem direito ao repouso semanal remunerado de vinte e quatro horas consecutivas, preferentemente aos domingos, nos limites das exigências técnicas das empresas, nos feriados civis e religiosos de acordo com a tradição local.

${ }^{11}$ Art. 7a. São direitos dos trabalhadores urbanos e rurais, além de outros que visem a melhoria de sua condição social: [...] XV - Repouso semanal remunerado, preferencialmente aos domingos.

${ }^{12} \mathrm{Da}$ indústria, do comércio, transporte, comunicações, publicidade, educação, cultura, serviços funerários, limpeza, alimentação de animais, sendo que outros setores necessitam de autorização do Ministério do Trabalho.

13 "Art. 9". Nas atividades em que não for possível, em virtude das exigências técnicas das empresas, suspensão do trabalho, nos dias de feriados civis e religiosos, a remuneração será paga em dobro, salvo se o empregador determinar outro dia de folga." 
estimulada pelo texto constitucional. Dois meses depois, aquele governo editou a MP 1.539-36, de 2.10.97, permitindo o trabalho do comércio aos domingos desde que o descanso semanal coincidisse com um domingo pelo menos 1 vez a cada 4 semanas, sempre respeitada a negociação coletiva. Esta MP foi transformada na Lei 10.101/2000, a qual não sofreu censura do STF.

Nos últimos capítulos dessa novela, o atual Governo Lula, no dia 5 de setembro de 2007, editou a MP 388/2007, permitindo o trabalho aos domingos no comércio em geral, desde que o descanso semanal coincida com o domingo a cada três semanas e, desde que observada a legislação municipal. A MP em questão foi aprovada pelo Congresso Nacional por meio da Lei n. 11.603, de 5 de dezembro de 2007.

Saliente-se que as atividades do comércio em geral não se coadunam com as razões legais previstas no ordenamento jurídico para o funcionamento regular aos domingos, ou seja, as atividades não podem ser tidas como de conveniência pública, necessidade imperiosa do serviços ou de exigências técnicas como condições peculiares da empresa ou em razão do interesse público que tornem indispensável a continuidade do serviço.

O que se vê é o aparato legal, aos poucos, se desmantelando pela banalização de todos os fundamentos mencionados para privilegiar o consumismo aos domingos. E, surpreendentemente, mesmo diante de uma legislação constitucional e ordinária que privilegia a negociação coletiva e de um governo cujo presidente foi o maior líder sindical da história do Brasil, a negociação coletiva, que poderia conter ainda alguns abusos, foi menosprezada como forma de solução, restando aos representantes municipais, de forma amplamente discricionária, o poder de validar e ponderar sobre tais divergências: de um lado o direito de descanso dos trabalhadores e de outro o crescente consumo. Em outras palavras, a regularidade do descanso aos domingos foi ceifada da vida dos comerciários.

\subsection{Dificuldades no Acesso ao Judiciário pelos Sindicatos}

Os conflitos coletivos são solucionados de várias formas, pela autodefesa que se expressa por meio da greve, redução do ritmo de trabalho, boicote, sabotagem, campanhas publicitárias, piquetes, etc.; pela autocomposição, conhecida como negociação coletiva; e pela heterocomposição, cuja solução se dá por meio de um terceiro suprapartes que decidirá a controvérsia, esta solução é conhecida como arbitragem, mediação ou solução jurisdicional.

No conflito processual e judicial, denominado dissídio coletivo, provocada a função judiciária do Estado, este decide, o que 
significa uma delegação de poderes ao judiciário trabalhista para, utilizando a via processual, criar ou modificar norma jurídica, numa atividade mista, sob a forma externa de procedimento judicial, agasalha em seu bojo uma real manifestação legislativa. (GIGLIO, 1993, p. 107).

No Brasil, a CF/88 ao discorrer sobre a competência, a Justiça, no art. $114^{14}$, salientava que o sindicato interessado, uma vez frustrada a negociação coletiva, poderia ajuizar dissídio coletivo na Justiça do Trabalho para estabelecer normas e condições, respeitadas as disposições convencionais e legais mínimas de proteção ao trabalho.

O poder normativo condicionado à prévia autorização da lei, é previsto desde a Constituição de 1946. A Constituição revogada (CF/1967, art. 142, $\left.\S 1^{115}\right)$ declarava que a lei deveria especificar as hipóteses em que as decisões, nos dissídios coletivos, poderiam estabelecer normas e condições de trabalho. A Constituição de 1988 retirou essa condição e autorizou a Justiça do Trabalho a estabelecer normas e condições, portanto não apenas condições de trabalho, mas outras também, por exemplo, cláusulas obrigacionais entre sindicatos conflitantes (NASCIMENTO, 1994, p. 383).

É destacável que a Justiça do Trabalho obteve aumento de sua competência a partir da CFD 88; mas, retrocedendo, a Emenda n. 45, de dezembro de 2004, alterou a redação do $\S 2{ }^{a}$., do art. 114 da CFD 88, que passou a ter a seguinte redação:

${ }^{14}$ Art. 114. Compete à Justiça do Trabalho conciliar e julgar os dissídios individuais e coletivos entre trabalhadores e empregadores, abrangidos os entes de direito público externo e da administração pública direta e indireta dos Municípios, do Distrito Federal, dos Estados e da União, e, na forma da lei, outras controvérsias decorrentes da relação de trabalho, bem como, os litígios que tenham origem no cumprimento de suas próprias sentenças, inclusive coletivas.

$\S 1^{\underline{a}}$ Frustrada a negociação coletiva, as partes poderão eleger árbitros.

§2 $2^{\underline{a}}$ Recusando-se qualquer das partes à negociação ou à arbitragem, é facultado aos respectivos sindicatos ajuizar dissídio coletivo, podendo a Justiça do Trabalho estabelecer normas e condições, respeitadas as disposições convencionais e legais mínimas de proteção ao trabalho.

${ }^{15}$ Art. 142. Compete à Justiça do Trabalho conciliar e julgar os dissídios individuais e coletivos entre empregados e empregadores e, mediante lei, outras controvérsias oriundas de relação de trabalho.

$\S 1^{\underline{a}}$ A lei especificará as hipóteses em que as decisões, nos dissídios coletivos, poderão estabelecer normas e condições de trabalho. 
Art. 114 [...]

$\S 2^{a}$. Recusando-se qualquer das partes à negociação coletiva ou à arbitragem, é facultado às mesmas, de comum acordo, ajuizar dissídio coletivo de natureza econômica, podendo a Justiça do Trabalho decidir o conflito, respeitadas as disposições mínimas legais de proteção ao trabalho, bem como as convencionadas anteriormente.

Ora, para ter acesso à Justiça, o sindicato dos trabalhadores que ficar impossibilitado de concluir uma negociação coletiva mediante uma simples recusa do empregador ou seu representante sindical, para acessar a Justiça, terá que "de comum acordo" com o sindicato patronal propor dissídio coletivo. Acrescente-se que o Tribunal Superior do trabalho firmou entendimento ${ }^{16}$ sobre o significado da condição de "comum acordo" para promoção de dissídio, como sendo petição em conjunto na promoção da ação judicial:

Segundo o advogado, pelo proponente, na ADIN 3423/2005, Sid Riedel, tal dispositivo da reforma do Judiciário ( $\$ 2^{\underline{a}}$ do art. 114) é inconstitucional, pois contraria cláusulas pétreas da Constituição, que asseguram o direito a qualquer pessoa ao acesso a Justiça (art. $5^{\mathrm{a}}$, XXXV). Enaltecendo sua indignação, o advogado faz a seguinte comparação: "Imagine uma pessoa que me deve R\$ 5.000. Tento resolver o problema negociando, mas a pessoa não me paga. Aí quero entrar na Justiça, mas só posso recorrer ao Judiciário se essa pessoa estiver de acordo". (BARBOSA, 2006, p. 336).

Noutro exemplo, considerando que o texto constitucional (art. 7aㅗ IV), prevendo que o salário deve ter reajustes periódicos que the preservem o poder aquisitivo, caso o sindicato dos trabalhadores proponha negociação apenas para o reajuste anual dos salários, isto é, de que seu interesse não vai além do limite mínimo constitucional e, diante da recusa do sindicato patronal à negociação e com a recusa do mesmo em propor de "comum acordo" um dissídio coletivo, o sindicato dos trabalhadores não tem acesso à Casa $d a$ Justiça que, nesta hora, estará de portas fechadas. É a lei! Mas é a lei de quem?

O legislador constitucional cedeu às alegações de que as decisões normativas se mostravam ineficientes, porque neutralizavam a greve como instituto de pressão e equilíbrio nas relações de Trabalho, de que os dissídios coletivos bloqueavam a livre negociação coletiva, impedindo a criação autônoma das normas trabalhistas pelos próprios interessados (SILVA, 1993).

\footnotetext{
${ }^{16}$ Sobre esta questão, ver o "Dissídio Coletivo no. 165049D 2005-000-00-00.4”.
} 
Com o afastamento do Estado nos conflitos coletivos, com a mitigação das decisões normativas, tem-se, portanto, a normatização do programa neoliberal. Se as sentenças normativas impediam o equilíbrio das negociações coletivas, porque neutralizavam as greves como instrumento de pressão, sem elas não se tem mais dissídio coletivo, não se tem mais greve e não se tem mais negociação. Noutras palavras, o trabalhador, por meio de seu sindicato, não tem, também, acesso à justiça, pois o Estado não intervém mais; aliás, intervém, caso haja "comum acordo" das partes para acesso à solução heterônoma do Estado.

Os defensores do fim do poder normativo também argumentavam que as sentenças normativas tinham a forma de uma lei e que o judiciário não tem a função legislativa. Saliente-se, que o direito é múltiplo. E é múltiplo porque necessita de outras ciências. E é uno, porque a justiça é uma só. Não existe, nesse passo, poder judiciário, poder legislativo, poder executivo; o que existe é o Estado e as suas funções respectivas, o Estado também é um só. Tanto é que, a função judiciária do Estado legisla administrativamente e internamente em seus órgãos, a função executiva legisla, como é o caso das medidas provisórias e das normas regulamentadoras; e a função legislativa julga, seja pelas Comissões Processantes de Inquérito, seja em caráter administrativo, seja no caso de suspensões de mandatos de parlamentares ou de membros da função executiva. Mas, ironicamente, quando se trata de atender direitos dos trabalhadores, as decisões normativas se transformam em desvio de função do judiciário.

Não é difícil concluir que além de uma mitigação da competência da Justiça do Trabalho nos conflitos coletivos, os dissídios coletivos e as sentenças normativas, que poderiam justificar ganhos aos trabalhadores que sequer conseguem reajustes salariais, tornaram-se institutos decorativos no ordenamento jurídico. Assim, o sindicato não conquista a negociação coletiva, não consegue a greve, que atualmente só é deflagrada no serviço público em face da segurança proporcionada pela estabilidade de emprego, e não tem sequer a Justiça do Estado para se socorrer.

\section{CONSIDERAÇÕES FINAIS}

A investigação aos institutos aqui destacados nos leva a considerar que, após as graves perdas identificadas a partir do ano de 2003, há continuidade na adequação do Estado brasileiro aos determinantes neoliberais periféricos, cujos princípios arrocham sobremodo a pasta trabalhista, ampliando o lucro dos grandes capitais e reduzindo conquistas históricas como as aqui 
demonstradas no estudo: como a mitigação do acesso à justiça aos sindicatos por meio do dissídio coletivo, do desconto em folha de pagamento de salários a favor do capital financeiro e na ampliação do módulo semanal de trabalho para os comerciários, fomentada pela abertura do comércio aos domingos.

\section{REFERÊNCIAS}

BARBOSA, Renato Lima. O poder normativo da justiça do trabalho e a emenda constitucional n. 45/2004. 2006. 174f. Tese (Doutorado em Direito das Relações Sociais) - Universidade Federal do Paraná, Curitiba, 2006.

BERNARDES, Roberto C. A inovação no capitalismo contemporâneo. São Paulo em Perspectiva, São Paulo, v. 12, n. 2, p. 33-45, abr./jun., 1998.

BESSA, César. Meios de proteção ao salário. 1998. 271f. Dissertação (Mestrado em Direito Negocial) - Universidade Estadual de Londrina, Londrina, 1998.

BORON, Atílio A. A sociedade civil depois do dilúvio neoliberal. In SADER, Emir; GENTILI, Pablo. Pós-neoliberalismo: as políticas sociais e o Estado democrático. 5. ed. Rio de Janeiro: Paz e Terra, 2000. p. 63-118.

CESARINO JÚNIOR, Antônio F.; CARDONE, Marly A. Direito Social: teoria geral do direito social, direito contratual do trabalho, direito protecionista do trabalho. 2. ed. São Paulo: LTr, 1993.

CUEVA, Agustin. A guinada conservadora. In: (Org.). Tempos conservadores: a direitização no ocidente e na América Latina. São Paulo: Hucitec, 1989. p. 19-37.

DELGADO, Mauricio G.. Curso de direito do trabalho. 6. ed. São Paulo: LTr, 2007.

DIAS, Edmundo F. A liberdade (im)possível na ordem do capital: reestruturação produtiva e passivização. 2. ed. Campinas, São Paulo: IFCH/ UNICAMP, 1999. (Textos Didáticos; n. 29).

GIGLIO, Wagner. Direito Processual do Trabalho. 8. ed. São Paulo: Ltr., 1993. GOMES, Orlando. O salário no direito brasileiro. São Paulo: LTr., 1996.

HARVEY, David. A Condição Pós-Moderna. 9. ed. São Paulo: Loyola, 2000. HUBERMAN, Leo. História da Riqueza do Homem. 21. ed. Rio de Janeiro: Guanabara, 1986. 
IANNI, Otávio. Globalização e neoliberalismo. São Paulo em Perspectiva, São Paulo, v. 12, n. 2, p. 27-32, abr./jun., 1998.

LEITE, Márcia de P. Reestruturação produtiva, novas tecnologias e novas formas de gestão da mão-de-obra. In: OLIVEIRA, Carlos A. B. et al. (Org.). $O$ Mundo do Trabalho: crise e mudança no final do século. São Paulo: MTb/ PNUD/CESIT-UNICAMP: Página Aberta, 1994. p. 563-587.

NASCIMENTO, Amauri Mascaro. Curso de direito do trabalho. 15. ed. São Paulo: Saraiva. 1994.

. Direito sindical. 2. ed. São Paulo: Saraiva, 1991.

OLEA, Manuel A. Introdução ao Direito do Trabalho. Curitiba: Gênesis, 1997.

OLIVEIRA, Francisco de. Neoliberalismo à brasileira. In. SADER, Emir; GENTILI, Pablo. Pós-Neoliberalismo: as políticas sociais e o Estado democrático. 5. ed. Rio de Janeiro: Paz e Terra, 2000. p. 24-34.

SILVA, Antonio Álvares da. Questões polêmicas de direito do trabalho. São Paulo: Ltr: 1993. v. 2.

SINGER, Paul. Para além do neoliberalismo: a saga do capitalismo contemporâneo. São Paulo em Perspectiva, São Paulo. v.1 2, n. 2, p. 3-20, abr./ jun. 1998.

SOJA, Edward W. Geografias Pós-Modernas: a reafirmação do espaço na teoria social crítica. Rio de Janeiro: Zahar, 1993.

SUSSEKIND, Arnaldo. Convenções da OIT. 2. ed. São Paulo: LTr, 1998.

TAVARES, Maria da Conceição. Globalitarismo e neobobismo. Folha de São Paulo, São Paulo, 30 mar. 1997. p. 2-5. 